\title{
Spinal Cord Astrocytoma
}

National Cancer Institute

\section{Source}

National Cancer Institute. Spinal Cord Astrocytoma. NCI Thesaurus. Code C4641.

A low or high grade astrocytoma that arises in the spinal cord. 